\title{
Synthesis of Carbon Nanotube/Graphene Composites on Ni Foam without Additional Catalysts by CVD and their Nitrogen-Plasma Treatment for Anode Materials in Lithium-ion Batteries
}

\section{Chuen-Chang LIN* and Ping-Lin CHANG}

\author{
Department of Chemical \& Materials Engineering, National Yunlin University of Science and Technology, \\ 123 University Road Sec. 3, Douliu, Yunlin 64002, Taiwan
}

*Corresponding author: linchuen@yuntech.edu.tw

\begin{abstract}
To simultaneously synthesize carbon nanotubes and graphene on nickel foam without additional catalysts, one-step ambient pressure chemical vapor deposition (CVD) is used to grow them at different temperatures. Next, adding nitrogen-doped defects to the surface of the carbon nanotube/graphene composites, the carbon nanotube/ graphene composites are modified by RF (radio frequency) nitrogen-plasma treatment at different power levels and time periods. Carbon nanotubes and graphene are simultaneously synthesized by CVD at $800^{\circ} \mathrm{C}$. Furthermore, the specific capacity $\left(618 \mathrm{mAh}^{-1}\right.$ ) reaches a maximum at the nitrogen-plasma treatment conditions (power $=100 \mathrm{~W}$ and time $=15 \mathrm{~min})$. Moreover, it also shows the nearly double improvement of the specific capacity and higher electrochemical stability after carbon nanotube/graphene composites are treated by nitrogen-plasma.
\end{abstract}

(c) The Electrochemical Society of Japan, All rights reserved.

Keywords : Carbon Nanotube/Graphene Composites, Chemical Vapor Deposition, Nitrogen-Doped, Lithium-ion Batteries

\section{Introduction}

The applications of lithium-ion batteries include portable electronic devices, electric vehicles, and hybrid electric vehicles. Compared to other batteries (such as Ni-Cd, Lead-Acid, and Ni$\mathrm{MH})$, lithium-ion batteries possess higher energy densities (100$150 \mathrm{Wh} \mathrm{kg}^{-1}$ ), higher voltage, and lower maintenance. ${ }^{1}$ The energy density and performance of lithium-ion batteries mainly depend on the properties of anode and cathode materials. In this research, we focused on anode materials of lithium-ion batteries.

Carbon nanotubes (CNTs) have nanometer size, hollow structure, low ratio of micropores, high accessible surface area, low resistance, and high stability. ${ }^{2}$ Graphene has larger accessible specific surface area in comparison with CNTs as well as activated carbon and higher electronic conductivity in comparison with activated carbon as well as CNTs. ${ }^{3-5}$ These properties make them potentially suitable for anode materials of lithium-ion batteries.

Thicker graphene results from higher growth temperature. ${ }^{6}$ The thickness of graphene films can be synthesized under control by chemical vapor deposition (CVD) on polycrystalline copper; the number of layers of graphene increases as temperature increases. ${ }^{7}$ The layer spacing between the graphene nanosheets controlled through interacting functional nanocarbons such as CNTs might be crucial for enhancement of the storage capacity. ${ }^{8}$ The CNTs can act as the spacer in fabricating a three-dimensional hierarchical structure with graphene sheets, thus enhancing its effective surface area and capacitance performance. ${ }^{9}$ The multiwalled carbon nanotubes in the graphene/multiwalled carbon nanotube film can efficiently increase the basal spacing and bridge the defects for electron transfer between graphene sheets, thus increasing electrolyte/electrode contact area and facilitating transportation of electrolyte ion as well as electron into the inner region of electrode. ${ }^{10}$ Three-dimensional CNTs/graphene sandwich structures with CNTs pillars grown in between the graphene layers were prepared by CVD; the unique structure possessed the high-rate transportation of electrolyte ions and electrons throughout the electrode matrix since the introduction of CNTs can provide diffusion path for electrolyte ions on the surface of graphene and the interconnection of CNTs with graphene can form a conductive network for the transport of electrons. ${ }^{11}$

Vertically aligned CNTs were directly grown by CVD $(60 \mathrm{sccm}$ $\mathrm{C}_{2} \mathrm{H}_{2}, 120 \mathrm{sccm} \mathrm{H}_{2}, 200 \mathrm{sccm} \mathrm{Ar}, 750^{\circ} \mathrm{C}$ ) on graphene paper coated with $\mathrm{Fe}$ and $\mathrm{Al}_{2} \mathrm{O}_{3}$; a higher and more stable discharge capacity in comparison with graphene paper and CNTs was achieved. ${ }^{12}$ Hybrid CNTs and graphene nanostructures applied in lithium ion batteries were directly grown by ambient pressure $\mathrm{CVD}$; methane was introduced to form graphene on copper foils at $950^{\circ} \mathrm{C}$, then $\mathrm{Fe}$ catalysts were deposited on graphene/copper foils by e-beam evaporation, and ethylene was next introduced to grow pillar CNTs on graphene/copper foil at $750^{\circ} \mathrm{C}$. $^{13}$ The CNTs-graphene hybrid materials were synthesized on an oxygen-plasma treated copper film coated with $\mathrm{Fe}$ catalysts by e-beam evaporation through a one-step CVD process using a mixture of acetylene and hydrogen at 650 torr for 10 to $20 \mathrm{~min} .{ }^{14}$ Vertically grown multiwalled CNTs on a single layer graphene floor were synthesized by a one-step acetyleneCVD process on copper foil (catalysts for graphene growth) coated with $\mathrm{Fe}$ (catalysts for multiwalled CNTs growth) by e-beam evaporation. ${ }^{15}$ To increase the accessible specific surface area and the stability as well as conductivity between the carbon nanotube bundles as well as the nickel foam, three dimensional few layer graphene/multi-walled carbon nanotube architectures were fabricated on oxygen-plasma treated nickel foam coated with Fe catalysts by e-beam evaporation through a one-step ambient pressure CVD process using a mixture of acetylene and hydrogen. ${ }^{16}$ The CNTsgraphene hybrid materials were grown by simple one-step ambient pressure CVD on copper foil spin-coated with silicon nanoparticles using ethanol as precursor at different temperatures and the density of CNTs can be controlled by the CVD growth temperature. ${ }^{17}$

$\mathrm{N}$-doped graphene sheets with the nitrogen-doping level as high as $7.04 \%$ synthesized by thermal annealing pristine graphene sheets with low-cost industrial material melamine exhibited higher initial reversible capacity $\left(1123 \mathrm{mAhg}^{-1}\right)$ at $50 \mathrm{~mA} / \mathrm{g}$ than that $\left(848 \mathrm{mAh} \mathrm{g}^{-1}\right)$ for pristine graphene sheets due to the topological 
defects and the existence of pyridinic nitrogen atoms on the graphene sheets. ${ }^{18} \mathrm{~N}$-doped graphene materials prepared by CVD technique using acetonitrile as liquid precursor and then under an ammonia atmosphere exhibited nearly double reversible discharge capacity in comparison with pristine graphene because of the large number of surface defects induced by $\mathrm{N}$-doping. ${ }^{19} \mathrm{~N}$-doped multiwall carbon nanotubes prepared by a plasma enhanced CVD process contain wall defects through which lithium ions can diffuse so as to occupy a large portion of the interwall space as storage regions and then improve the $\mathrm{Li}$ storage capability. ${ }^{20} \mathrm{~N}$-doped graphene nanosheets prepared by heat treatment $\left(800^{\circ} \mathrm{C}\right.$ and $\left.2 \mathrm{~h}\right)$ of graphite oxide under an ammonia atmosphere exhibited a high reversible capacity due to $\mathrm{N}$-doping inducing a large number of defects on the graphene layer as well as then forming a disordered carbon structure (further enhancing Li intercalation properties) and enhanced cycling stability, which demonstrated the N-doped graphene nanosheets to be a promising candidate for anode materials of lithium ion batteries. ${ }^{21}$ The effects of the electron-deficiency (making the defect graphenes have an electron-accepting tendency) of N-doped (pyridinic, pyrrolic, and graphitic) graphenes on their application in lithium ion batteries were investigated and the pyridinic graphene possessed the best as anode materials of lithium ion batteries, while graphitic graphene would be the weakest of the three defect structures. ${ }^{22}$

The main aim of this research was to simultaneously synthesize carbon nanotubes as well as graphene on nickel foam without additional catalysts by CVD at different temperatures and then add nitrogen-doped defects to the surface of carbon nanotube/graphene composites by RF nitrogen-plasma treatment at different power levels and periods of time.

\section{Experiment}

Nickel foam with three dimensional conductive network structure working as template for the growth of graphene facilitated easy access of electrolyte ions to the electrode surface. ${ }^{23,24}$ The use of $\mathrm{Ni}$ foam is known to increase the active material utilization of the electrode, and thus the specific capacitance of the electrode with the $\mathrm{Ni}$ foam current collector was higher than that with the $\mathrm{Ti}$ mesh current collector. ${ }^{23,24}$ The Nickel foam $\left(1 \times 2 \times 0.1 \mathrm{~cm}^{3}\right)$ was degreased ultrasonically $(40 \mathrm{kHz})$ in acetone for $15 \mathrm{~min}$. Next, it was rinsed ultrasonically $(40 \mathrm{kHz})$ with pure de-ionized water for $15 \mathrm{~min}$, and then oven-dried in air $\left(50^{\circ} \mathrm{C}\right)$ to constant weight.

First, the pretreated nickel foam substrate was heated at $1000^{\circ} \mathrm{C}$ in $\mathrm{H}_{2}(100 \mathrm{sccm})$ and $\mathrm{Ar}(250 \mathrm{sccm})$ for $10 \mathrm{~min}$ to reduce the surface oxide layer. Next, to simultaneously synthesize carbon nanotubes and graphene on nickel foam without additional catalysts, one-step ambient pressure CVD was used to grow them on the annealed nickel foam with a gas mixture of $\mathrm{C}_{2} \mathrm{H}_{2}(15 \mathrm{sccm}), \mathrm{H}_{2}(100 \mathrm{sccm})$, as well as $\operatorname{Ar}(250 \mathrm{sccm})$ for $10 \mathrm{~min}$ at different temperatures $(700,800$, and $900^{\circ} \mathrm{C}$ ) and then cooling to ambient temperatures in Ar with the same volume flow rate as carbon nanotube/graphene composites grown. Finally, the carbon nanotube/graphene composites were weighed.

The carbon nanotube/graphene composites were placed in the reaction chamber $\left(85 \mathrm{~cm}^{3}\right)$ of the apparatus for RF plasma treatment (frequency: $13.56 \mathrm{MHz}$ and maximum power: $1000 \mathrm{~W}$ ). Then, the chamber was vacated to $10^{-3}-10^{-4} \mathrm{mbar}$. Next, $20 \mathrm{sccm}$ of nitrogen gas and $10 \mathrm{sccm}$ of argon gas were introduced to the chamber to maintain its pressure at 0.174 mbar. Finally, adding nitrogen-doped defects to the surface of the carbon nanotube/graphene composites, the carbon nanotube/graphene composites were modified by nitrogen-plasma at different power levels $(50,100$, and $150 \mathrm{~W}$ ) and periods of time $(5,15$, and $30 \mathrm{~min})$, and then reweighed.

A solution of $1 \mathrm{M} \mathrm{LiPF}_{6}$ dissolved in 1:1:1 (v/v) ethylene carbonate (EC)-ethyl methyl carbonate (EMC)-dimethyl carbonate (DMC) from Ubiq Technology was used as the electrolyte. The anode electrode (Li metal: 99.9\%, $0.3 \mathrm{~mm}$ thick, Ubiq Technology) was assembled with the cathode electrode (carbon nanotube/ graphene composites or carbon nanotube/graphene composites treated by nitrogen-plasma) into a coin cell by using a coin cell manual crimping machine (CR2032, Taiwan) in an Ar-filled glovebox. The electrochemical cycling tests were performed with a voltage range of $0.01-3 \mathrm{~V}$ using a cycler (PFX 2011, Kikusui, Japan). The current density is about $41.5-61.8 \mathrm{~mA} \mathrm{~g}^{-1}(0.1 \mathrm{C})$ and the measurement temperature is ambient temperature.

The micrographs of CNTs grown at $700^{\circ} \mathrm{C}$, carbon nanotube/ graphene composites synthesized at $800^{\circ} \mathrm{C}$, and graphene grown at $900^{\circ} \mathrm{C}$ were conducted by field emission scanning electron microscope (FE-SEM: JEOL JSM-6700F, Japan). Furthermore, the D peak intensity, the $\mathrm{G}$ peak intensity, as well as the $2 \mathrm{D}$ peak intensity of CNTs grown at $700^{\circ} \mathrm{C}$, carbon nanotube/graphene composites synthesized at $800^{\circ} \mathrm{C}$, as well as graphene grown at $900^{\circ} \mathrm{C}$ and the $\mathrm{I}_{\mathrm{D}} / \mathrm{I}_{\mathrm{G}}$ of carbon nanotube/graphene composites without nitrogenplasma as well as with nitrogen-plasma (power $=100 \mathrm{~W}$ and time $=$ $15 \mathrm{~min})$ were investigated by microscopic Raman spectrometer (inVia, Renishaw, England). Moreover, functional groups (pyridinic$\mathrm{N}$, pyrrolic-N and graphitic-N) of carbon nanotube/graphene composites modified by nitrogen-plasma at different power levels and periods of time were explored by XPS (Fison VG. ESCA210, England). Finally, impedance measurement was performed using an electrochemical analyzer (CH Instruments $\mathrm{CHI} 608 \mathrm{~B}$, USA) at $5 \mathrm{mV}$ $\mathrm{AC}$ amplitude with a frequency range between $100 \mathrm{kHz}$ and $0.01 \mathrm{~Hz}$ to measure the charge transfer resistance for carbon nanotube/ graphene composites before cycling and obtain the charge transfer resistance as well as the solid electrolyte interface (SEI) film resistance using the supposed equivalent circuit to fit EIS data by an EC-Lab demo (EC-LAB Electrochemistry, Bio-Logic Science Instruments, French) for carbon nanotube/graphene composites after the third cycle due to requiring first three cycles to get proper SEI film on the active mass. Cyclic voltammetry tests for carbon nanotube/graphene composites without nitrogen-plasma and with nitrogen-plasma (power $=100 \mathrm{~W}$ and time $=15 \mathrm{~min}$ ) were performed using an electrochemical analyzer $(\mathrm{CH}$ Instruments $\mathrm{CHI}$ $608 \mathrm{~B}, \mathrm{USA})$ at a scan rate of $0.1 \mathrm{mV} \mathrm{s}^{-1}$ over a potential range of 0.01 to $3.0 \mathrm{~V}$ (vs. $\mathrm{Li}^{+} / \mathrm{Li}$ ).

\section{Results and Discussion}

CNTs were grown at $700^{\circ} \mathrm{C}, \mathrm{CNTs}$ as well as graphene sheets were simultaneously synthesized at $800^{\circ} \mathrm{C}$, and graphene sheets were grown at $900^{\circ} \mathrm{C}$ (See Fig. 1). Furthermore, the higher the $\mathrm{I}_{\mathrm{D}} / \mathrm{I}_{\mathrm{G}}$ [See Figs. 2(a) and 2(b)], the higher the content of defects, which can be attributed to CNTs [See Figs. 1(a) and 1(b)]. ${ }^{25}$ The presence of the $G$ peak as well as the $2 \mathrm{D}$ peak and the $\mathrm{I}_{\mathrm{G}} / \mathrm{I}_{2 \mathrm{D}}$ [See Figs. 2(b) and 2(c)] indicate the typical Raman characteristics for few-layer graphene sheets [See Figs. 1(b) and 1(c)]. ${ }^{16}$

Figure 3 shows the effects of nitrogen-plasma power and time on the specific capacity at the second cycle of carbon nanotube/ graphene composites. The specific capacity $\left(618 \mathrm{mAh}^{-1}\right)$ reached a maximum at the nitrogen-plasma treatment conditions (power = $100 \mathrm{~W}$ and time $=15 \mathrm{~min}$ ) which possessed the highest atomic percentage of $\mathrm{N}$ (See Table 1). The higher the percentage of the pyridinic-N, the higher the specific capacity (See Figs. 3 and 4) since the pyridinic-N results in the improvement of the capacity, ${ }^{21}$ the pyridinic defect structure is the most suitable for Li storage with a high storage capacity ${ }^{22}$ and the binding energy with ion for the pyridinic- $\mathrm{N}$ is the largest. ${ }^{26}$ Therefore, the specific capacity is proportional to the natural logarithm of the pyridinic-N\% $\left(\mathrm{R}^{2}=\right.$ 0.9963, See Fig. 5). For the functional groups of carbon nanotube/ graphene composites modified by nitrogen-plasma, the binding energy values for pyridinic-N, pyrrolic-N and graphitic-N are 398.5, 400.1, and $401.5 \mathrm{eV}$, respectively. ${ }^{27}$ Furthermore, the 2nd discharge 
(a)

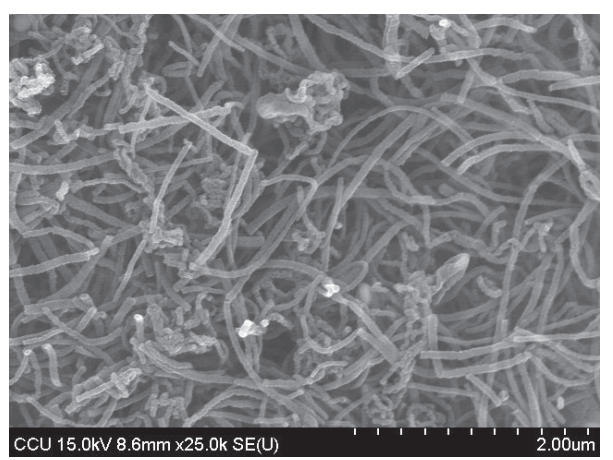

(b)

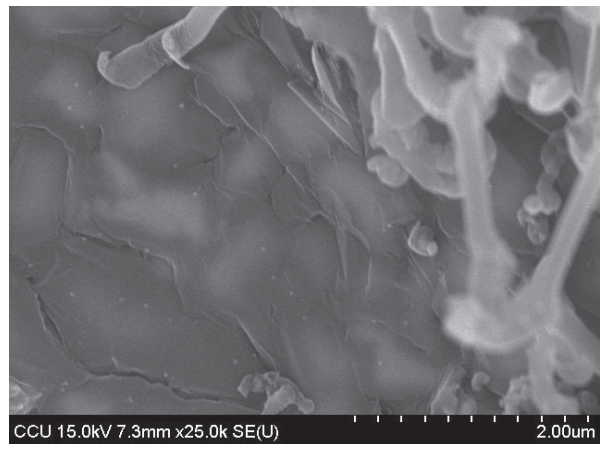

(c)

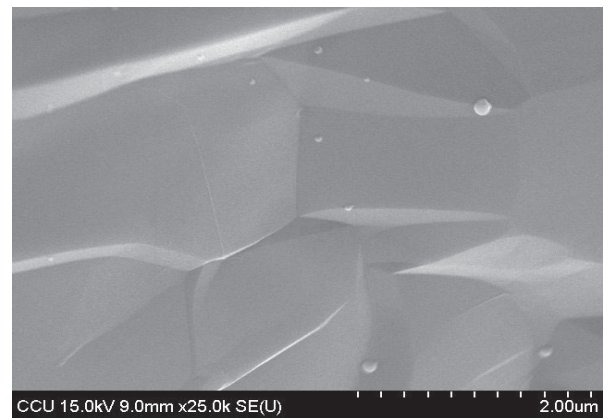

Figure 1. The FESEM images of (a): CNTs grown at $700^{\circ} \mathrm{C}$, (b): CNTs and graphene sheets simultaneously synthesized at $800^{\circ} \mathrm{C}$, and (c): graphene sheets grown at $900^{\circ} \mathrm{C}$.

profiles of carbon nanotube/graphene composites treated by nitrogen-plasma at different periods of time (power levels $=100 \mathrm{~W}$ ) and different power levels (periods of time $=15 \mathrm{~min}$ ) are shown in Figs. 6(a) and 6(b), respectively. All discharge curves are similar except differently specific capacity which is shown in Fig. 3. Moreover, the 1st coulombic efficiency (specific capacity of 2 nd charge divided by specific capacity of 1 st discharge) for carbon nanotube/graphene composites is about $75.33 \%$. However, the 1st coulombic efficiency (See Fig. 7) for carbon nanotube/graphene composites being treated by nitrogen-plasma decreases in comparison with that for carbon nanotube/graphene composites. The reason behind this behavior may be explained as follows. After carbon nanotube/graphene composites being treated by nitrogen-plasma, $\mathrm{N}$-doping can induce a large number of topological defects, ${ }^{21}$ and then enhance the surface area of carbon nanotube/graphene composites, which leads to increasing the irreversible capacity since a large surface area probably also increases electrolyte decomposition and then forms a SEI film on the surface of electrodes. ${ }^{18,19,28}$ The higher the atomic percentage of $\mathrm{N}$, the lower the 1st coulombic efficiency (See Table 1 and Fig. 7). (a)

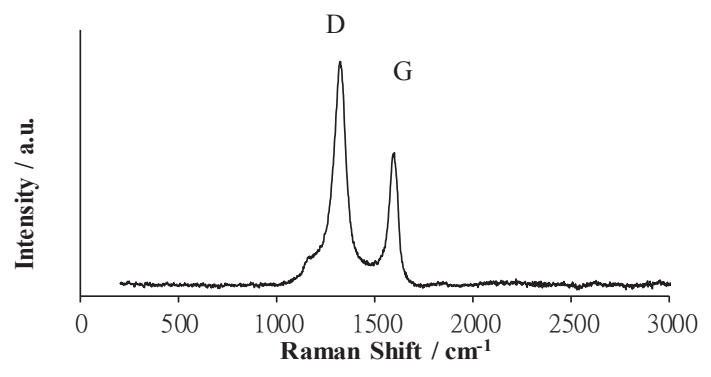

(b)

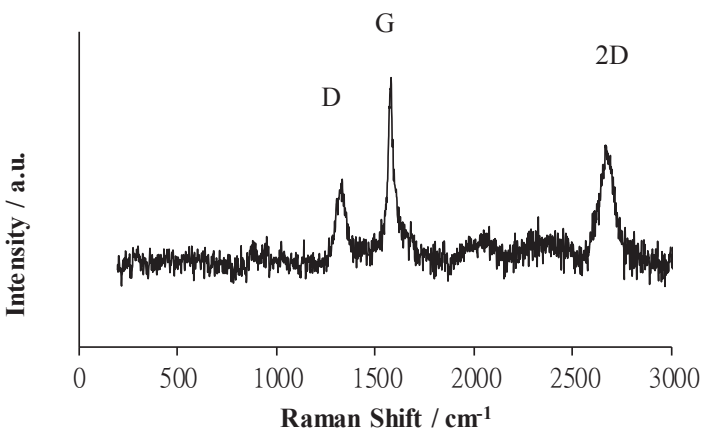

(c)

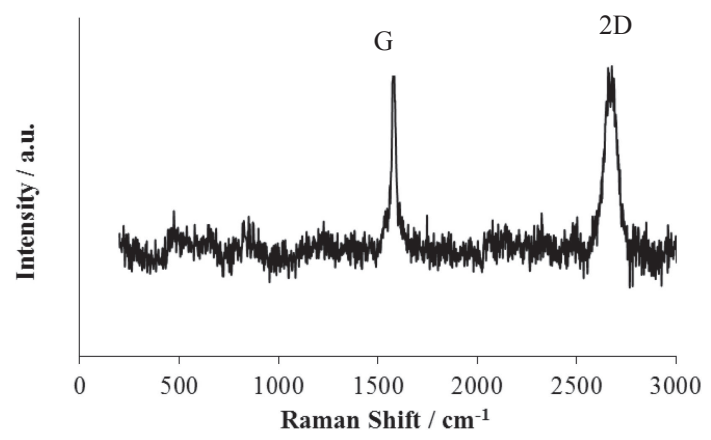

Figure 2. Raman spectra of (a): CNTs, (b): CNTs and graphene sheets, and (c): graphene sheets.

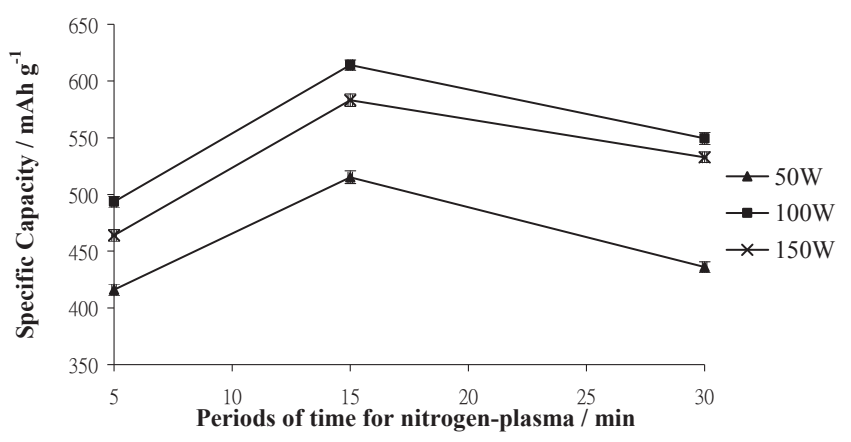

Figure 3. The effects of nitrogen-plasma power and time on the specific capacity at the second cycle of carbon nanotube/graphene composites (the average values and deviations were obtained from three samples prepared by exactly the same procedures).

The discharge/charge profiles of carbon nanotube/graphene composites and carbon nanotube/graphene composites treated by nitrogen-plasma (power $=100 \mathrm{~W}$ and time $=15 \mathrm{~min}$ ) are shown in Figs. 8(a) and 8(b). Since the crystallinity of carbon nanotube/ graphene composites is probably poor, their potential plateaus in the first discharge curves in Figs. 8(a) and 8(b) are not distinct, which 
Table 1. The effects of nitrogen-plasma power and time on the atomic percentage of $\mathrm{C}, \mathrm{N}$, and $\mathrm{O}$.

\begin{tabular}{ccccc}
\hline Power/W & Time/min & $\mathrm{C} /$ at\% & $\mathrm{N} /$ at $\%$ & $\mathrm{O} / \mathrm{at} \%$ \\
\hline \multirow{3}{*}{$50 \mathrm{~W}$} & 5 & 83.78 & 2.6 & 13.62 \\
& 15 & 82.79 & 3.64 & 13.57 \\
& 30 & 86.84 & 2.97 & 10.19 \\
\hline \multirow{3}{*}{$100 \mathrm{~W}$} & 5 & 85.97 & 3.5 & 10.54 \\
& 15 & 84.71 & 6.33 & 8.96 \\
\hline \multirow{3}{*}{$150 \mathrm{~W}$} & 30 & 87 & 4.64 & 8.36 \\
& 5 & 83.08 & 3.15 & 13.78 \\
& 15 & 85.09 & 5.16 & 9.75 \\
& 30 & 83.12 & 3.97 & 12.91 \\
\hline
\end{tabular}

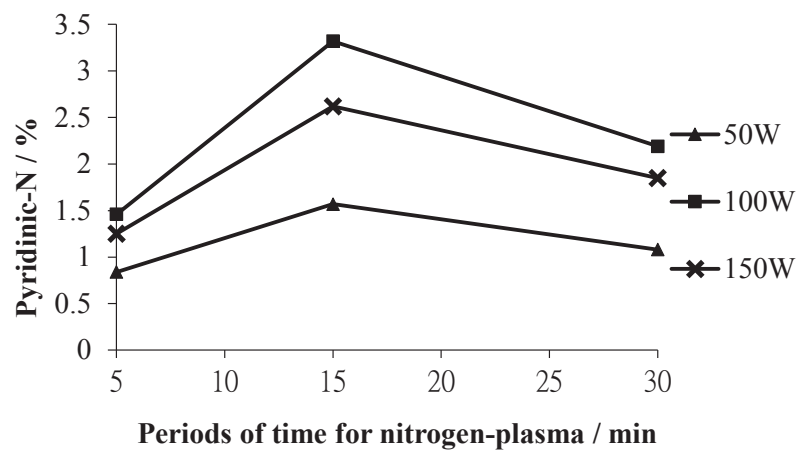

Figure 4. The effects of nitrogen-plasma power and time on the percentage of the pyridinic- $\mathrm{N}$ of carbon nanotube/graphene composites.

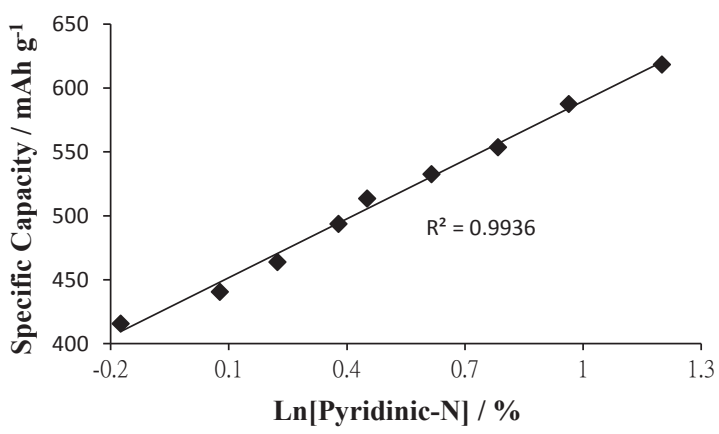

Figure 5. The correlation between the specific capacity and the natural logarithm of the pyridinic-N\%.

also is observed for porous carbon. ${ }^{29}$ For carbon nanotube/graphene composites treated by nitrogen-plasma, its discharge specific capacity $\left(618 \mathrm{mAh}^{-1}\right)$ at the 2 nd cycle is much higher than that $\left(338 \mathrm{mAhg}^{-1}\right)$ of carbon nanotube/graphene composites [See Figs. 8(a) and $8(\mathrm{~b})$ ]. If discharge specific capacity $\left(200 \mathrm{mAh}^{-1}\right)$ at the 2 nd cycle is same, it occurs at higher potential (about $0.4 \mathrm{~V}$ ) for carbon nanotube/graphene composites treated by nitrogenplasma and at lower potential (about $0.1 \mathrm{~V}$ ) for carbon nanotube/ graphene composites [See Figs. 8(a) and 8(b)]. The discharge curves at the 2 nd cycle and the 10th cycle in Figs. 8(a) and 8(b) are almost overlapped. Therefore, the difference of discharge capacity between the 2 nd cycle and the 10th cycle in Fig. 11 is very small since possibly irreversible lithium loss (the side reaction of electrolyte decomposition and then formation of a SEI film) ${ }^{28}$ is also very small in comparison with the 1st cycle. Furthermore, the anode electrode (a)

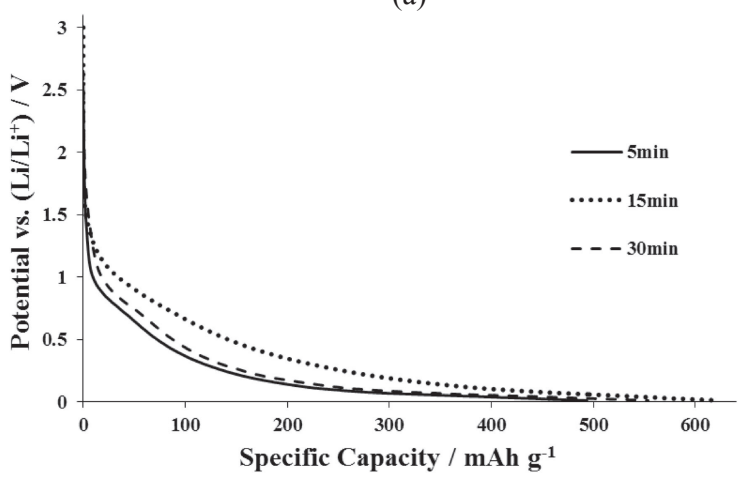

(b)

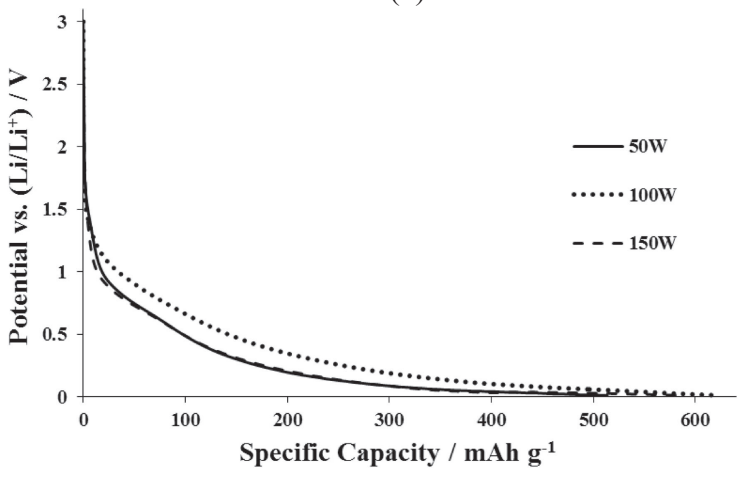

Figure 6. The 2nd discharge profiles of carbon nanotube/ graphene composites treated by nitrogen-plasma at (a) different periods of time (power levels $=100 \mathrm{~W}$ ) and (b) different power levels (periods of time $=15 \mathrm{~min}$ ).

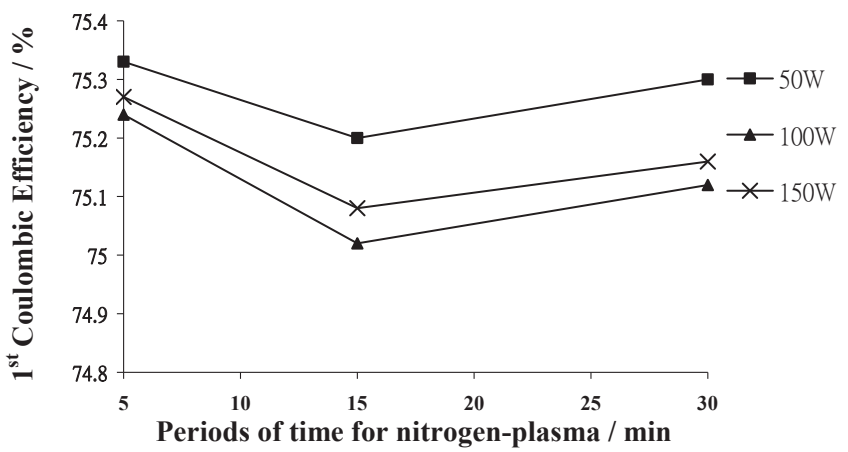

Figure 7. The effects of nitrogen-plasma power and time on the 1 st coulombic efficiency of carbon nanotube/graphene composites.

(Li metal) was assembled with the cathode electrode (carbon nanotube/graphene composites or carbon nanotube/graphene composites treated by nitrogen-plasma) into a coin cell and their charge processes almost occurred at lower voltage (below $0.5-1.0 \mathrm{~V}$ ) [See Figs. 8(a) and 8(b)] in this research. Therefore, if carbon nanotube/ graphene composites or carbon nanotube/graphene composites treated by nitrogen-plasma was as an anode electrode for lithiumion batteries, their discharge processes should almost occur at higher voltage for the benefit of merchantable lithium-ion batteries. Moreover, before charge-discharge test, the diameter of the semicircle in the high and middle frequency range $(5 \mathrm{~Hz}-100 \mathrm{kHz})$ [See Fig. 9(a)] indicated charge-transfer resistance (about $13.6 \mathrm{ohm}$ ) and the distance between the origin of the $\mathrm{z}^{\prime}$ axis and the semicircle indicated electrolyte resistance (about $3.9 \mathrm{ohm}$ ) (See Table 2). After the third cycle, the semicircle in the high frequency range $(>1 \mathrm{kHz}$, SEI film resistance) and the semicircle in the middle frequency range 
(a)

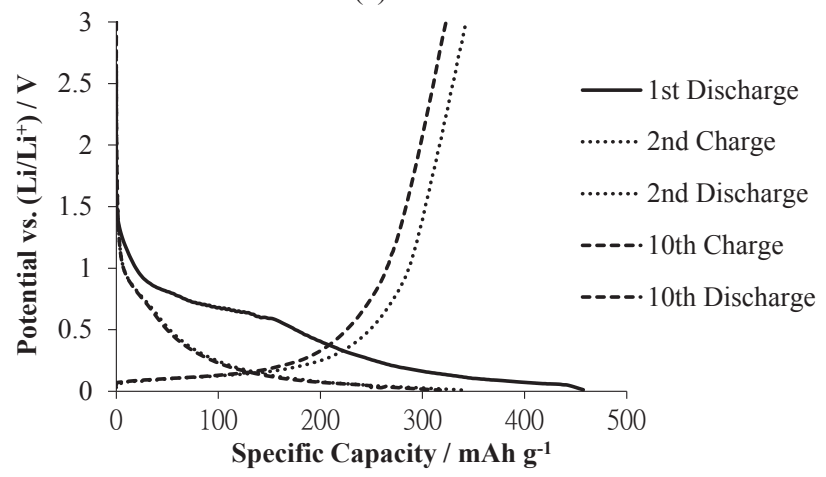

(b)

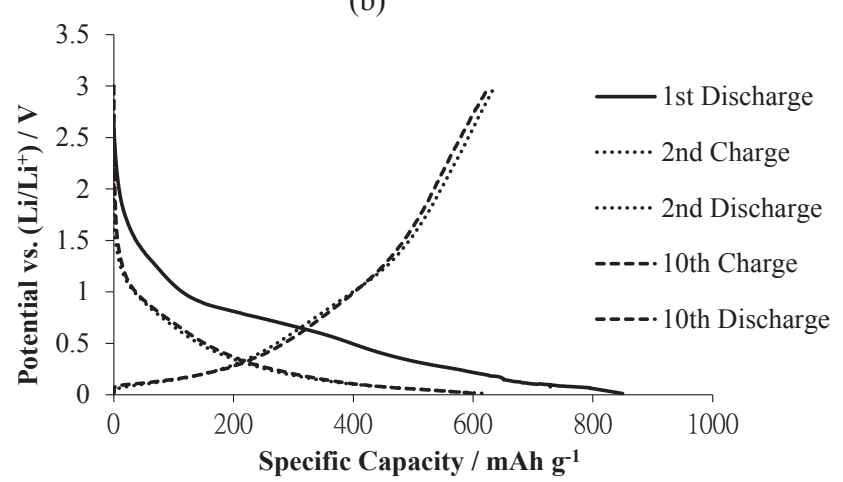

Figure 8. The discharge/charge profiles of (a): carbon nanotube/ graphene composites and (b): carbon nanotube/graphene composites treated by nitrogen-plasma (power $=100 \mathrm{~W}$ and time $=15 \mathrm{~min}$ ).

Table 2. Parameter values observed from Fig. 9(a) for carbon nanotube/graphene composites before charge-discharge test.

\begin{tabular}{cc}
\hline Parameter & Value \\
\hline $\mathrm{R}_{\mathrm{s}} / \Omega$ & 3.9 \\
$\mathrm{R}_{\mathrm{SEI}} / \Omega$ & 0.0 \\
$\mathrm{R}_{\mathrm{ct}} / \Omega$ & 13.6 \\
\hline
\end{tabular}

(5 Hz-1 kHz, charge-transfer resistance) were separated. ${ }^{29}$ The detail characterizations were further analyzed by fitting the measured impedance data [See Fig. 9(b)] using the supposed equivalent circuit [See Fig. 9(c)]. Then the charge transfer resistance (about $6.7 \mathrm{ohm}$ ) and the SEI film resistance (about $3.2 \mathrm{ohm}$ ) were obtained after the third cycle (See Table 3). After cycling, the wetting of the electrode by the electrolyte could be improved due to aging as well as continuous electrochemical interaction and then led to lower charge transfer resistance, ${ }^{29}$ so the charge transfer resistance before cycling is higher than the charge transfer resistance after the third cycle (See Tables 2 and 3). Finally, the reactions for the anode electrode ( $\mathrm{Li}$ metal) and the cathode electrode (carbon nanotube/graphene composites and carbon nanotube/graphene composites treated by nitrogen-plasma) are same and shown in the following: ${ }^{30}$

$$
\begin{aligned}
& \text { Cathode: } 6 \mathrm{C}+x \mathrm{Li}^{+}+x \mathrm{e}^{-} \leftrightarrow \mathrm{C}_{6} \mathrm{Li}_{x} \\
& \text { Anode: } x \mathrm{Li} \leftrightarrow x \mathrm{Li}^{+}+x \mathrm{e}^{-} \\
& \text {Overall reaction: } 6 \mathrm{C}+x \mathrm{Li} \leftrightarrow \mathrm{C}_{6} \mathrm{Li}_{x}
\end{aligned}
$$

Since both carbon nanotube/graphene composites and carbon nanotube/graphene composites treated by nitrogen-plasma exhibit similar behaviors [See Figs. 10(a) and 10(b)], which also are observed for graphene and nitrogen-doped graphene. ${ }^{31}$ The board peaks [i.e. the potential plateaus in the first discharge curves of (a)

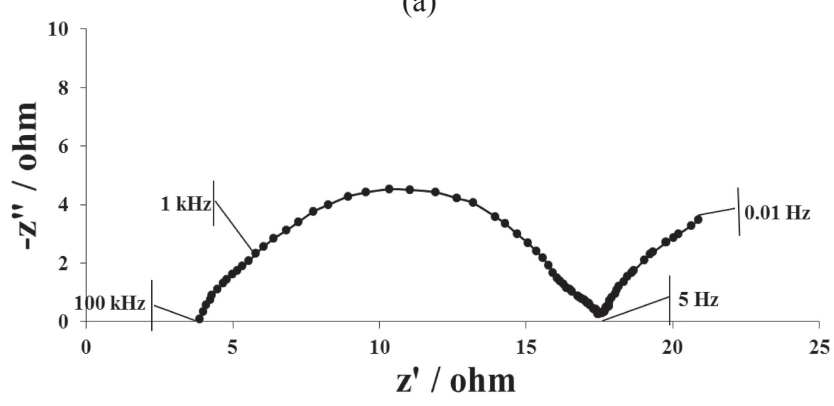

(b)

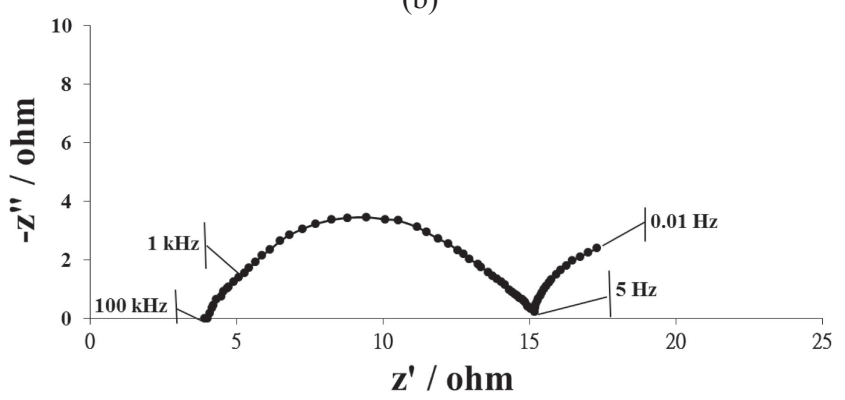

(c)

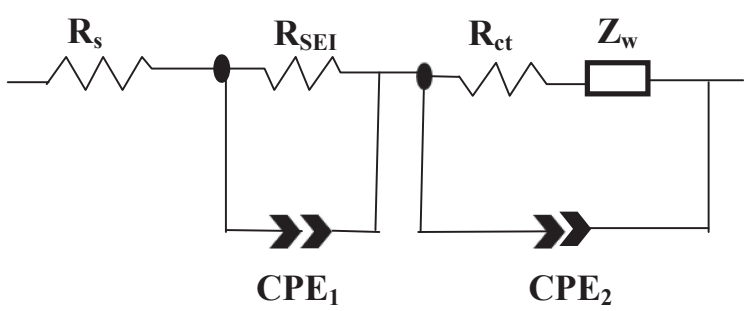

Figure 9. (a) Nyquist diagram $\left(\mathrm{R}_{\mathrm{ct}}=13.6 \mathrm{ohm}\right)$ of carbon nanotube/graphene composites before cycling, (b) Nyquist diagram $\left(\mathrm{R}_{\mathrm{ct}}=6.7 \mathrm{ohm}\right.$ and $\left.\mathrm{R}_{\mathrm{SEI}}=3.2 \mathrm{ohm}\right)$ of carbon nanotube/graphene composites after the third cycle, and (c) Supposed equivalent circuit used to fit EIS data for carbon nanotube/graphene composites after the third cycle $\left(\mathrm{R}_{\mathrm{s}}\right.$ : ', $\mathrm{R}_{\mathrm{SEI}}$ : $\mathrm{SEI}$ film resistance, $\mathrm{R}_{\mathrm{ct}}$ : charge-transfer resistance, $Z_{\mathrm{w}}$ : Warburg impedance, $\mathrm{CPE}_{1}$ : SEI film capacitance, and $\mathrm{CPE}_{2}$ : double layer capacitance).

Table 3. Component values of the supposed equivalent circuit used to fit EIS data for carbon nanotube/graphene composites after the third cycle.

\begin{tabular}{ll}
\hline Component & \multicolumn{1}{c}{ Fitted value } \\
\hline $\mathrm{R}_{\mathrm{s}} / \Omega$ & $4.2 \pm 0.08$ \\
$\mathrm{R}_{\mathrm{SEI}} / \Omega$ & $3.2 \pm 0.04$ \\
$\mathrm{CPE}_{1} / \mathrm{F}$ & $(9.1 \pm 0.096) \times 10^{-6}$ \\
$\mathrm{R}_{\mathrm{ct}} / \Omega$ & $6.7 \pm 0.02$ \\
$\mathrm{CPE}_{2} / \mathrm{F}$ & $(35.1 \pm 0.07) \times 10^{-6}$ \\
$\mathrm{Z}_{\mathrm{w}} / \mathrm{Ohm} \mathrm{s}^{1 / 2}$ & $2.2 \pm 0.06$ \\
\hline
\end{tabular}

Figs. 8(a) and 8(b) are not distinct] for carbon nanotube/graphene composites and carbon nanotube/graphene composites treated by nitrogen-plasma nearly occur at the same potential (about $0.5 \mathrm{~V}$ ) during the first discharge scan [See Figs. 10(a) and 10(b)] due to formation of a SEI film and disappear in the following cycles. The peaks for carbon nanotube/graphene composites and carbon nanotube/graphene composites treated by nitrogen-plasma nearly locate at the same potential [close to $0 \mathrm{~V}$, i.e. the potential plateaus in the 


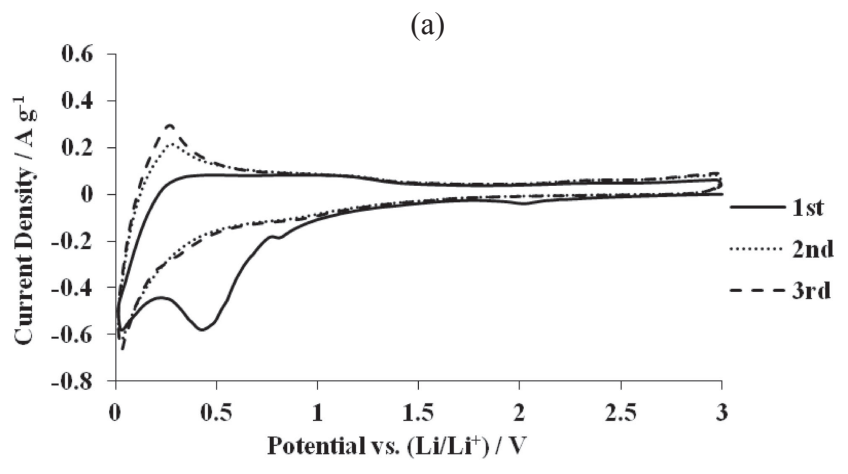

(b)

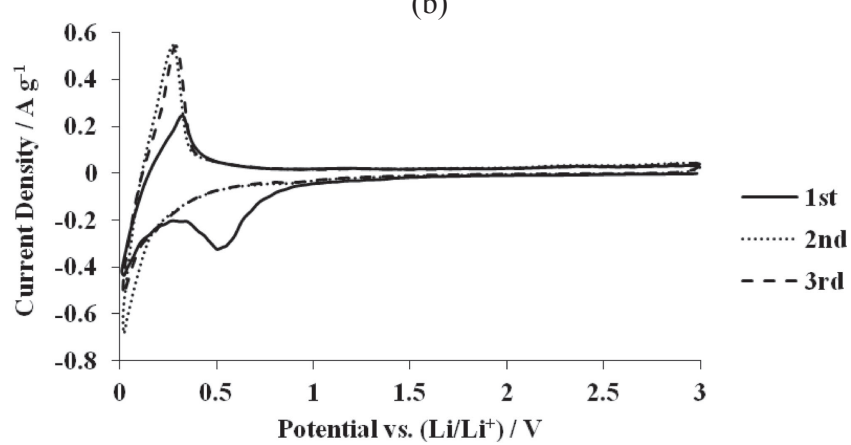

Figure 10. Cyclic voltammograms (from the 1st cycle to the 3rd cycle) of (a): carbon nanotube/graphene composites and (b): carbon nanotube/graphene composites with nitrogen-plasma (power $=$ $100 \mathrm{~W}$ and time $=15 \mathrm{~min}$ ).

discharge curves of Figs. 6(a), 6(b), 8(a) and 8(b)] that can result from the $\mathrm{Li}^{+}$intercalation into the carbon composites [See Figs. 10(a) and 10(b)]. The peaks for carbon nanotube/graphene composites and carbon nanotube/graphene composites treated by nitrogen-plasma nearly occur at the same potential [about $0.3 \mathrm{~V}$, i.e. the potential plateaus in the charge curves of Figs. 8(a) and 8(b)] that can be attributed to the $\mathrm{Li}^{+}$de-intercalation from the carbon composites [See Figs. 10(a) and 10(b)]. Those are similar to the peaks for carbon nanotubes. ${ }^{32}$

Figure 11 shows the effects of carbon nanotube/graphene composites without nitrogen-plasma as well as with nitrogen-plasma (power $=100 \mathrm{~W}$ and time $=15 \mathrm{~min}$ ) and different charge-discharge cycles on the specific capacity. The specific capacity of carbon nanotube/graphene composites treated by nitrogen-plasma was higher than the specific capacity of carbon nanotube/graphene composites. The reason behind this behavior may be explained as follows. The $\mathrm{I}_{\mathrm{D}} / \mathrm{I}_{\mathrm{G}}$ (1.01) of carbon nanotube/graphene composites treated by nitrogen-plasma is larger than the $\mathrm{I}_{\mathrm{D}} / \mathrm{I}_{\mathrm{G}}(0.62)$ of carbon nanotube/graphene composites (See Fig. 12). After N-doping, the $\mathrm{I}_{\mathrm{D}} / \mathrm{I}_{\mathrm{G}}$ increases which demonstrates some disordered carbon in carbon materials (i.e. introduces more defect sites). ${ }^{32}$ Thus the larger the $\mathrm{I}_{\mathrm{D}} / \mathrm{I}_{\mathrm{G}}$, the more the defect of carbon nanotube/graphene composites, ${ }^{33}$ and then the higher the surface area of carbon nanotube/graphene composites, which leads to increasing the specific capacity. The carbon nanotube/graphene composites treated by nitrogen-plasma also contain wall defects through which lithium ions can diffuse so as to occupy a large portion of the interwall space as storage regions and then improve the Li storage capability. ${ }^{20}$ After carbon nanotube/graphene composites being treated by nitrogenplasma, N-doping can induce a large number of topological defects and then form a disordered carbon structure that further enhances Li intercalation properties. ${ }^{21}$ The extra capacity over the theoretical capacity $\left(372 \mathrm{mAh} \mathrm{g}^{-1}\right)$ is considered to come from the contribution of cavities or defects. ${ }^{34,35}$ Therefore, the $x$ in the cathode reaction

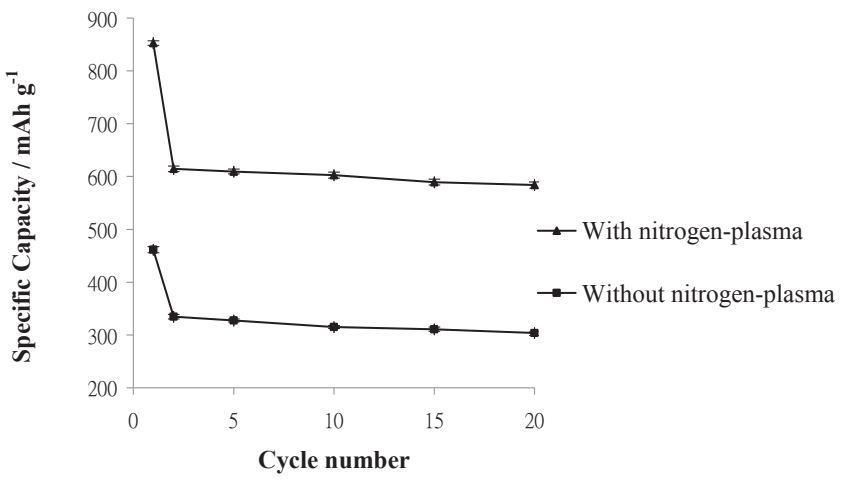

Figure 11. The effects of carbon nanotube/graphene composites without nitrogen-plasma as well as with nitrogen-plasma (power $=$ $100 \mathrm{~W}$ and time $=15 \mathrm{~min}$ ) and different charge-discharge cycles on the specific capacity (the average values and deviations were obtained from two samples prepared by exactly the same procedures).

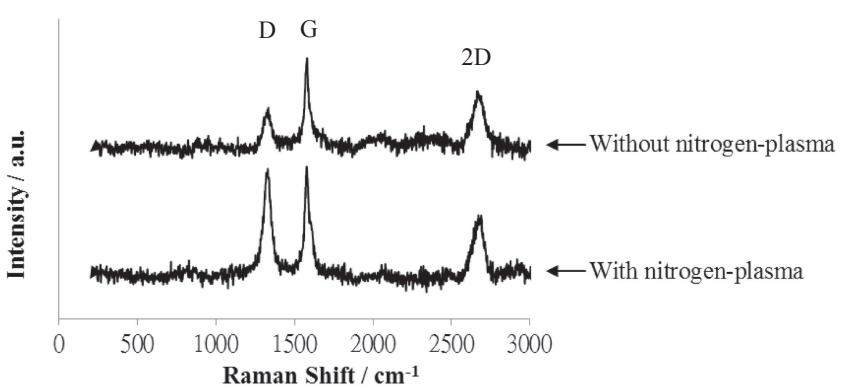

Figure 12. Raman spectra of carbon nanotube/graphene composites without nitrogen-plasma and with nitrogen-plasma (power $=$ $100 \mathrm{~W}$ and time $=15 \mathrm{~min}$ ).

$\left(6 \mathrm{C}+x \mathrm{Li}^{+}+x \mathrm{e}^{-} \leftrightarrow \mathrm{C}_{6} \mathrm{Li}_{x}\right)$ for carbon nanotube/graphene composites treated by nitrogen-plasma is larger than one, then its specific capacity is higher than the theoretical capacity $\left(372 \mathrm{mAhg}^{-1}\right.$ correspond to $x=1$ in $\left.\mathrm{C}_{6} \mathrm{Li}_{x}\right) \cdot{ }^{36}$ Furthermore, it also shows the nearly double improvement of the specific capacity and higher electrochemical stability (specific capacity only decreased 5\% from the 2 nd cycle to the 20th cycle) after carbon nanotube/graphene composites being treated by nitrogen-plasma in comparison with carbon nanotube/graphene composites (specific capacity decreased $10 \%$ from the 2 nd cycle to the 20th cycle) (See Fig. 11).

\section{Conclusions}

A higher percentage of the pyridinic-N led to higher specific capacity due to the pyridinic defect structure being the most suitable for Li storage with a high storage capacity; then the specific capacity is proportional to the natural logarithm of the pyridinic-N\%. Furthermore, the specific capacity of carbon nanotube/graphene composites treated by nitrogen-plasma was higher than the specific capacity of carbon nanotube/graphene composites. Moreover, discharge processes of carbon nanotube/graphene composites or carbon nanotube/graphene composites modified by nitrogen-plasma as an anode electrode of lithium-ion batteries should almost occur at lower potential for the benefit of merchandising.

\section{Acknowledgments}

Financial support by the Ministry of Science and Technology of the Republic of China (under grant no. MOST 104-2221-E-224047-) is gratefully acknowledged. 


\section{References}

1. D. Miranda, C. M. Costa, and S. Lanceros-Mendez, J. Electroanal. Chem., 739, 97 (2015).

2. J. H. Chen, W. Z. Li, D. Z. Wang, S. X. Yang, J. G. Wen, and Z. F. Ren, Carbon, 40, 1193 (2002).

3. P. Simon and Y. Gogotsi, Acc. Chem. Res., 46, 1094 (2013).

4. S. J. Chae, F. Günes, K. K. Kim, E. S. Kim, G. H. Han, S. M. Kim, H. J. Shin, S. M. Yoon, J. Y. Choi, M. H. Park, C. W. Yang, D. Pribat, and Y. H. Lee, $A d v$. Mater, 21, 2328 (2009).

5. N. R. Franklin, Q. Wang, T. W. Tombler, A. Javey, M. Shim, and H. Dai, Appl. Phys. Lett., 81, 913 (2002).

6. W. Liu, C. H. Chung, C. Q. Miao, Y. J. Wang, B. Y. Li, L. Y. Ruan, K. Patel, Y. J. Park, J. Woo, and Y. H. Xie, Thin Solid Films, 518, S128 (2010).

7. Z. Tu, Z. Liu, Y. Li, F. Yang, L. Zhang, Z. Zhao, C. Xu, S. Wu, H. Liu, H. Yang, and P. Richard, Carbon, 73, 252 (2014).

8. E. Yoo, J. Kim, E. Hosono, H. S. Zhou, T. Kudo, and I. Honma, Nano Lett., 8, 2277 (2008).

9. Y. Wang, Y. Wu, Y. Huang, F. Zhang, X. Yang, Y. Ma, and Y. Chen, J. Phys. Chem. C, 115, 23192 (2011).

10. X. Lu, H. Dou, B. Gao, C. Yuan, S. Yang, L. Hao, L. Shen, and X. Zhang, Electrochim. Acta, 56, 5115 (2011).

11. Z. Fan, J. Yan, L. Zhi, Q. Zhang, T. Wei, J. Feng, M. Zhang, W. Qian, and F. Wei, Adv. Mater., 22, 3723 (2010)

12. S. Li, Y. Luo, W. Lv, W. Yu, S. Wu, P. Hou, Q. Yang, Q. Meng, C. Liu, and H. M. Cheng, Adv. Energy Mater., 1, 486 (2011).

13. W. Wang, I. Ruiz, S. Guo, Z. Favors, H. H. Bay, M. Ozkan, and C. S. Ozkan, Nano Energy, 3, 113 (2014).

14. M. Ghazinejad, S. Guo, R. K. Paul, A. S. George, M. Penchev, M. Ozkan, and C. S. Ozkan, Mater. Res. Soc. Proc., 1344, mrss11-1344-y01-07 (2011).

15. Rajesh, R. K. Paul, and A. Mulchandani, J. Power Sources, 223, 23 (2013).

16. W. Wang, S. Guo, M. Penchev, I. Ruiz, K. N. Bozhilov, D. Yan, M. Ozkan, and C. S. Ozkan, Nano Energy, 2, 294 (2013).
17. X. Dong, B. Li, A. Wei, X. Cao, M. B. Chan-Park, H. Zhang, L. J. Li, W. Huang, and P. Chen, Carbon, 49, 2944 (2011).

18. D. Cai, S. Wang, P. Lian, X. Zhu, D. Li, W. Yang, and H. Wang, Electrochim. Acta, 90, 492 (2013).

19. A. L. M. Reddy, A. Srivastava, S. R. Gowda, H. Gullapalli, M. Dubey, and P. M. Ajayan, ACS Nano, 4, 6337 (2010).

20. W. H. Shin, H. M. Jeong, B. G. Kim, J. K. Kang, and J. W. Choi, Nano Lett., 12, 2283 (2012)

21. H. Wang, C. Zhang, Z. Liu, L. Wang, P. Han, H. Xu, K. Zhang, S. Dong, J. Yao, and G. Cui, J. Mater. Chem., 21, 5430 (2011).

22. C. Ma, X. Shao, and D. Cao, J. Mater. Chem., 22, 8911 (2012).

23. T. Xiao, X. Hu, B. Heng, X. Chen, W. Huang, W. Tao, H. Wang, Y. Tang, X. Tan, and X. Huang, J. Alloys Compd., 549, 147 (2013).

24. Y. Wang, A. Yuan, and X. Wang, J. Solid State Electrochem., 12, 1101 (2008).

25. S. Li, Y. Luo, W. Lv, W. Yu, S. Wu, P. Hou, Q. Yang, Q. Meng, C. Liu, and H. M. Cheng, Adv. Energy Mater, 1, 486 (2011).

26. H. Wang, T. Maiyalagan, and X. Wang, ACS Catal., 2, 781 (2012).

27. W. Fan, Y. E. Miao, Y. Huang, W. W. Tjiu, and T. Liu, RSC Adv., 5, 9228 (2015).

28. X. M. Liu, Z. D. Huang, S. W. Oh, B. Zhang, P. C. Ma, M. M. F. Yuen, and J. K. Kim, Compos. Sci. Technol., 72, 121 (2012).

29. Y. Han, L. Dong, J. Feng, D. Li, X. Li, and S. Liu, Electrochim. Acta, 167, 246 (2015).

30. P. Lv, H. Zhao, C. Gao, T. Zhang, and X. Liu, Electrochim. Acta, 152, 345 (2015).

31. X. Li, D. Geng, Y. Zhang, X. Meng, R. Li, and X. Sun, Electrochem. Commun., 13, 822 (2011).

32. W. Ren, D. Li, H. Liu, R. Mi, Y. Zhang, and L. Dong, Electrochim. Acta, 105, 75 (2013).

33. A. Umair and H. Raza, Nanoscale Res. Lett., 7, 437 (2012).

34. H. Fujimoto, A. Mabuchi, K. Tokumitsu, and T. Kasuh, J. Power Sources, 54, 440 (1995).

35. E. Peled, C. Menachem, D. Bar-Tow, and A. Melman, J. Electrochem. Soc., 143, L4 (1996).

36. Y. Liu, J. S. Xue, T. Zheng, and J. R. Dahn, Carbon, 34, 193 (1996). 